\title{
The Characteristics and Experiences of Canadian Students Receiving Special Education Services for a Learning Disability
}

\author{
Jessica Whitley \\ Lakehead University \\ Judy L. Lupart \\ University of Alberta \\ Tanya Beran \\ University of Calgary
}

\begin{abstract}
This article provides a description of the demographic characteristics as well as the social and academic experiences of a nationally representative sample of Canadian students receiving special education services for a learning disability (LD) and a comparison group without disabilities (NLD). Data summarized in this article were drawn from the National Longitudinal Survey of Children and Youth (NLSCY), which contains information provided by teachers, parents, and students. Results indicate that the demographic characteristics of the LD group are similar to the NLD group. As well, no significant differences were found between the self-reports of children in the LD and NLD groups regarding school and social experiences. However, differences exist in teachers 'perceptions of students' educational potential, social skills, and motivation. The findings inform school efforts focused on reducing the drop-out rate of students with $L D$. Other implications for practice as well as for future research are discussed.
\end{abstract}


Although educational and occupational outcomes have improved for students with learning disabilities (LD; National Longitudinal Transition Study-2 [NLTS-2], 2005), many students with LD continue to achieve at levels lower than their peers, are less likely to complete high school, and have social and academic self-concepts that are lower than average-achieving peers (NLTS-2, 2005; Nowicki, 2003; Smith \& Nagle, 1995; Vaughn, Elbaum, \& Boardman, 2001; Zeleke, 2004). Within the education system, students with LD represent the largest group of students receiving special education services in Canadian schools, comprising as high as $43 \%$ (e.g., British Columbia Ministry of Education, 2006; Ontario Ministry of Education and Training, 2005). Clearly, identifying variables that contribute to the continuing difficulties faced by students with LD is necessary if improvements are to be made in current practice. However, there has been no large scale systematic collection or publication of information with respect to the characteristics and school experiences of these students in Canada.

In recognition of the paucity of information that existed regarding students in special education, the Special Education Elementary Longitudinal Study (SEELS) was launched by the U.S. Department of Education in 2000. SEELS was also developed to be used as an indicator of the success of the Individuals with Disabilities Education Act (1997), which mandated the right of students with disabilities to a free appropriate public education in the least restrictive environment. Data from SEELS, including surveys completed by students, parents, and teachers, have begun to be analyzed and reports have been published in major academic journals (e.g., Wagner, Kutash, Duchnowski, \& Epstein, 2005; Wagner, Kutash, Duchnowski, Epstein, \& Sumi, 2005). The experiences of students with Emotional Disturbances have been the focus of the studies to date. These publications serve as a model for the present study.

While a study comparable to SEELS does not exist in Canada, there are a number of national surveys from which information can be drawn regarding students receiving special education services. The most relevant of these is the National Longitudinal Survey of Children and Youth (NLSCY). The NLSCY database contains nationally stratified data and is maintained jointly by Statistics Canada and Social Development Canada (SDC). According to Human Resources and Skills Development Canada (HRSDC, 1996),

The National Longitudinal Survey of Children and Youth (NLSCY) was developed with the objective of collecting data to identify risk factors for Canadian children, thereby improving society's understanding of the important process of child development. It is expected that information from the NLSCY will provide strategic insight for the formulation of more effective programs and policies for children at risk. (p. i) 
Data are collected every two years beginning in 1994-1995. The unit of analysis in the NLSCY is the child. Surveys are completed by the child's parents, teachers and, for children over the age of 10 , themselves. Topics within the surveys include the physical, emotional, and cognitive development of the child; parenting practices; education-related factors; and influences such as peers, schools and the larger community (Statistics Canada, 1997). Of particular relevance is the teacher survey which details whether the child is receiving special education services in school and for what difficulty or disability they are receiving these services. The present study will focus on the children who have been identified as receiving special education services because of a learning disability.

The term special education is one that holds varied meanings. While students with LD in the present study are receiving special education services, they may or may not be physically placed in a setting away from their sameaged peers. However, the majority of the research summarized in subsequent sections refer to special education "placement." For the purposes of the present study this term indicates that a student has been identified as requiring additional or specialized services in order to achieve at school and may receive additional funding and supports such as Individual Program or Education Plans as a result.

The school success of students with LD is impacted by myriad factors. Research focusing on a selection of these will be summarized in three sections: (a) demographic characteristics, (b) social experiences, and (c) academic/school experiences.

\section{Demographic Characteristics}

Gender. Boys have been found to be up to twice as likely as girls to receive special education services for LD (Oswald, Best, Coutinho, \& Nagle, 2003; SEELS, 2002). Explanations are both biological, such as hormonal or cognitive differences, and environmental, such as sex-stereotyped externalizing behaviour and subsequent teacher bias (Berry, Shaywitz, \& Shaywitz, 1985; Nass, 1993; Shaywitz, Towle, Keese, \& Shaywitz, 1990). More recent studies have focused on the underidentification of female students in the LD category and have expressed concern that because of the lower incidence of externalizing behaviours among girls, they are less likely to be referred and identified, and to receive appropriate services (Wehmeyer \& Schwartz, 2001). Gender will be included in the current analyses in light of previous findings demonstrating the influence of gender on special education placement for LD. 
Socioeconomic status. There is debate in the literature regarding the role of socio-economic status (SES) in the identification and subsequent special education placement of students with LD. Extensive U.S. evidence exists to support the relationship between SES, school readiness, and low school achievement (Duncan \& Brooks-Gunn, 1997; Lee \& Burkam, 2002). Specifically, students whose families have low incomes and less than high school education enter school with fewer academic skills and precursors for reading. These students often experience lower academic achievement over the long term and often cannot "catch-up" to their peers. Income, as one measure of SES, has also been found to influence academic and socio-emotional outcomes through its effect on mediating variables such as neighbourhood safety, quality of child care, and exposure to aggression and violence (Brody et al., 2001; Evans, 2004; Sampson, Raudenbush, \& Earls, 1997).

Connections between SES, school readiness, and environmental variables may in part explain why students in special education may often be from low-SES backgrounds. If students lack the academic preparation for school, and are not as well supported by caregivers and communities, they may experience difficulties that result in referrals for special education. Thus low-SES may be viewed as a determining factor, without which academic difficulties would not occur and LD placement would not result. However, given the definitional criteria for LD that include "genetic and/or neurobiological factors" (LDAC, 2002, p. 1), environmental influences such as SES should not theoretically result in a diagnosis of a learning disability. This perspective suggests that students from low-SES backgrounds are overrepresented in special education. The argument has also been made, however, that low-SES may serve as an additional risk factor, thus simply increasing the possibility that a student will be identified as LD (Blair \& Scott, 2002).

Researchers have attempted to examine more directly the influence of SES on special education placement. Skiba and his colleagues (Skiba, Poloni-Staudinger, Simmons, Feggins-Azziz, \& Chung, 2005) found that SES was a significant predictor of LD identification for students in one district of a Midwestern state. Specifically, students from low-SES backgrounds were significantly more likely to be placed in special education. Similarly, Blair and Scott (2002), using a set of records from the state of Florida, found that students from low-SES backgrounds were placed in special education for LD at a rate approximately $35 \%$ greater than students from middle- or high-SES backgrounds. Whatever the mechanism, then, evidence from U.S. studies indicates that students from low-SES backgrounds are placed in special education for LD at rates significantly higher than their peers. The current analysis will reveal if this is also the case for Canadian students in special education us- 
ing indicators of SES including family income, parent level of education, and neighbourhood safety ratings.

\section{Social Experiences}

Documenting the social experiences of students with LD greatly informs an understanding of the difficulties and poor school outcomes often faced by these students. Research has shown that students who maintain group membership, who have reciprocal friendships, and who perceive themselves as accepted by their peers experience higher academic self-concept, academic engagement, and achievement (Buhs, 2005; Buhs \& Ladd, 2001; Wentzel, Barry, \& Caldwell, 2004; Wentzel \& Caldwell, 1997). Students who exhibit prosocial classroom behaviours are also better liked by their teachers and in turn have higher grades (Wentzel, 1993; Wentzel \& Watkins, 2002).

The social skills deficits of students with LD have been documented for some time. Kavale and Forness (1996), in an oft-cited meta-analysis, concluded that "...about $75 \%$ of students with LD can be differentiated from their NLD peers through measures of social competence" (p. 233). Students with LD also rate their social self-concept as significantly lower than their average or highachieving peers (Nowicki, 2003; Smith \& Nagle, 1995). However Canadian literature in the area is sparse. In one study, Cadieux (1996) compared the social self-concept ratings of 386 French-Canadian students with and without LD and found no significant differences between groups. Whether or not students receiving special education services for LD in Canada are perceived by themselves and others as being socially competent and accepted has yet to be determined and will be explored in the present study.

\section{Academic/School Experiences}

Student perspective. The importance of school engagement and enjoyment to academic achievement and school completion has been demonstrated for students with and without disabilities (Buhs, 2005; Finn, 1993; Ontario Ministry of Education and Training, 2005; Sinclair, 1994). Students who are involved in their classroom and their school and who feel like they belong are more motivated and likely to expend effort in academic tasks (Karatzias, Power, Flemming, Lennan, \& Swanson, 2002). Thus, student perceptions of school enjoyment and belonging are important factors to be included in a description of the experiences of students receiving special education services for LD. 
Parent perspective. There is extensive evidence that parents' expectations or aspirations for their child's educational attainment have a significant impact on the achievement for students with and without LD. This effect has been shown in numerous studies to be mediated by parent behaviours (DavisKean, 2005; Englund, Luckner, Whaley, \& Egeland, 2004; Sy \& Schulenberg, 2005) and student expectations (Patrikakou, 1996). As well, parent involvement in student learning, including monitoring of homework, participation in school conferences and discussions surrounding future academic aspirations, has been found to be significantly related to achievement (Catsambis, 1998; Wang, Haertel, \& Walberg, 1990) and is an important factor in the success of students in special education.

Teacher perspective. Student achievement and self-concept have shown to be affected by teachers' perceptions of student potential, effort expended, social skills, and classroom behaviour (Birch \& Ladd, 1997; Boardman, 2005; Fuchs, Fuchs, \& Phillips, 1994; Jussim \& Harber, 2005; Meltzer et al., 2004). For students with disabilities in particular, those who are taught by teachers who believe that students with disabilities have the ability to learn and that interventions on the part of the teacher will promote said learning report significantly higher general self-concept (Jordan \& Stanovich, 2001).

As well, teachers' perceptions of parent involvement in their child's schooling has been shown to impact on their rating of student ability and achievement (Feinberg, 2001; Hughes, Gleason, \& Zhang, 2005). Parent involvement and collaboration has been made a priority by many provinces in terms of special education placement and planning (e.g., Alberta Learning, 2004; British Columbia Ministry of Education, 2000; Manitoba Education, Training and Youth, 2001; Nova Scotia Department of Education, 2003; Ontario Ministry of Education, 2006; Saskatchewan Learning, 2000). Thus for students in special education in particular, teacher perceptions of student potential and assessment of the extent to which parents are involved in their child's education are important factors in school success.

\section{Present Study}

The purpose of this article is to describe demographic characteristics, as well as social and academic variables that impact the potential success of students with LD. Teacher and parent reports, as well as student self-reports will be used to present a range of perspectives. This information will provide insight into the needs of students with LD and will help inform identification and intervention practices. The data summarized in this article, drawn from the 
NLSCY, represent a national sample of students and as such make a significant and unique contribution to existing literature.

\section{Method}

\section{Participants}

This sample includes a weighted sample of 4310 students in elementary and middle school who participated in the fourth cycle $(2000-2001)$ of the National Longitudinal Study of Child and Youth (NLSCY). Two groups of students (children enrolled in school) participated in the present study. The first group were students with learning disabilities (LD; $n=276$ ) who were identified through their teachers' response to a two-part question. First, teachers were asked, "Does this student receive special/resource help because a learning disability, a physical, emotional, behavioural, or other problem limits the kind or amount of school work he/she can do?" For teachers who responded in the affirmative, the following was asked: "What type of problem limits this student's ability to do school work in a regular classroom?" Those students for whom teachers replied with "learning disability" were included in the LD sample for the present study. Students identified as having multiple limitations (learning disability and another limitation) were excluded from the LD group. The second group consisted of students whose teachers did not identify them as receiving special/resource help for any reason (NLD; $n=4034)$.

\section{Measurement}

Items chosen from the NLSCY for inclusion in the present analysis consisted of a number of single survey questions as well as two scales comprised of multiple questions. Items were selected from three surveys: Parent, Child (referred to here as Student), and Teacher. The individual survey questions are presented in the analysis in their entirety and the scales are described below. In order to meet Statistics Canada guidelines for release of data, those response categories with coefficients of variance of 33.5 or higher were collapsed where possible to produce more acceptable estimates (Statistics Canada, 2001a, p. 135). For example, parents were asked the following question: "How far do you hope your child will go in school?" Parents responded on a 5-point scale, ranging from: 1 = complete some secondary or high school to $5=$ obtain a university degree. As few parents chose the lowest level of education, the lowest two levels (some secondary and secondary completion) were combined, resulting in a 4-point scale. 
The Neighbourhood Safety Scale assesses parents' perceptions of their neighbourhood in terms of safety at night and the availability of safe play spaces for their children. As such, it is an important aspect of assessing socioeconomic status. Parents responded to each of the following three questions on a 4-point scale ranging from $1=$ strongly disagree to $4=$ strongly agree: (a) Is it safe to walk alone in this neighbourhood after dark?, (b) is it safe for children to play outside during the day?, and (c) are there safe parks, playgrounds, and play spaces in this neighbourhood? Responses on the three questions were summed and then 1 point was subtracted from each item to create a scale score with a ceiling of nine with high scores indicating a high perception of neighborhood safety. The scale was adapted from the Simcha-Fagan Neighbourhood Questionnaire (Simcha-Fagan \& Schwartz, 1986) and has a Cronbach's Alpha of 0.70 (Statistics Canada, 2001a, p. 66).

The Social Skills scale was completed by teachers and was intended to measure social and personal skills demonstrated by the child in the class. The scale consisted of the following nine items which were rated on a 5-point scale ranging from $1=$ never to 5 = always: Please indicate how often this student: (a) works co-operatively with other students, (b) plays co-operatively with other students, (c) follows rules/instructions, (d) makes friends easily, (e) demonstrates self-control, (f) shows self-confidence, (g) shows respect for adults, (h) shows respect for other youth/children, and (i) accepts responsibility for his/her own actions. Teacher responses on the three questions were summed and then 1 point was subtracted from each item to create a scale score with a ceiling of 36 where high scores indicate strong social skills. NLSCY documents indicated that items for this scale were selected from a study by Freeman and Hatch (1989) and the Cronbach's alpha was reported as 0.93 (Statistics Canada, 2001b, p. 31), indicating good internal consistency.

\section{Analysis}

The NLSCY uses a complex sampling design which requires that weights be applied to the data in order to obtain accurate sample variance of survey estimates. The use of raw data to calculate estimates of population characteristics is not appropriate as it does not take into account the sampling design which is purposefully stratified rather than random (Statistics Canada, 2003). Accordingly, frequencies were calculated for students using WestVar 4.0 (Westat, 2000) and a set of cross-sectional Bootstrap weights provided by Statistics Canada. Using this procedure, the percentages reported are weighted population estimates which are nationally representative for the years when the data were collected (2000 and 2001). 
Descriptive analyses of the data were conducted. Specifically, the proportion of respondents that endorsed each level of categorical variables are presented for students in the LD and NLD groups. In addition, chi-square analyses with the RS2 adjustment for the design effect (Rao \& Scott, 1987) were conducted to determine whether the responses of the groups differed more greatly than would be expected by chance. A Bonferroni adjustment, relative to the number of multiple comparisons for each survey (Parent, Student, Teacher), was applied to the $p$ values as a conservative way to reduce the risk of finding false positive results and to maintain an overall alpha level of .05. Effect sizes were calculated for comparisons that were significantly different using Cohen's $w$ (Volker, 2006). For variables measured using a scale, two-tailed $t$ tests were conducted and if significantly different, effect sizes were calculated using Cohen's $d$ (Volker, 2006). All analyses were conducted using WesVar 4.0 (Westat, 2000).

\section{Results}

The results will be presented in three sections: (a) student and family characteristics, (b) social experiences, and (c) academic/school experiences. Within each of these, descriptive data will be presented for the LD and NLD groups. Data in the first section were provided solely by the participating parent of each student. Items in the second and third sections were completed by students, parents, and teachers.

\section{Student and Family Characteristics}

The characteristics of the students and their families are summarized in Table 1. Analyses indicated that there was a significantly greater proportion of boys in the LD than the NLD sample $(p<.02)$. As well, significantly greater numbers of parents of students in the NLD group had completed higher levels of education compared to the LD group $(p<.01)$. Income adequacy, which is calculated as a ratio of the number of persons in the household to household income, was not significant across groups. Finally, no differences were found between the mean neighbourhood safety scale scores of students in the LD and NLD groups, $t(4532)=1.11, p=.269$. 
Table 1

Student and Family Characteristics of Students in the LD and NLD Samples

\begin{tabular}{lccccc}
\hline & LD & NLD & & & \\
\cline { 2 - 3 } Characteristic & $\%$ & $\%$ & & $p$ & $w$ \\
\hline Gender & & & & & \\
$\quad$ Male & 62.41 & 47.60 & & & \\
$\quad$ Female & 37.59 & 52.40 & 9.14 & .02 & .046 \\
Parent's highest level of education & & & & & \\
$\quad$ Elementary & 23.78 & 9.67 & & & \\
$\quad$ Secondary & 21.76 & 25.99 & & & \\
$\quad$ Post-Secondary & 23.69 & 25.73 & & & .061 \\
$\quad$ University & 30.77 & 38.61 & & & \\
Income Adequacy & & & & & \\
Low & 10.60 & 6.75 & & & \\
$\quad$ Middle & 34.20 & 25.08 & & & \\
Upper Middle & 32.26 & 36.46 & 7.93 & .30 & -- \\
High & 22.94 & 31.71 & & & \\
\hline
\end{tabular}

Note: Bonferroni adjustment applied to $p$ values. Sample sizes for these analyses range from 273 to 276 for the LD group and 3969 to 4034 for the NLD group.

\section{Social Experiences}

Children in the LD and NLD groups report similar perceptions of their ability to make friends and of the extent to which peers desire their friendship. Likewise, parents of children in the LD group do not report significant differences in the number of close friends that their child has as compared to parents of children in the NLD group. However, differences can clearly be seen in teacher ratings of children's social skills. The mean social skills scale scores of the NLD group was significantly higher than the LD group, $t(2322)=5.84$, $p<.001, d=.516$. 
Table 2

Social Experiences of the LD and NLD Samples

\begin{tabular}{lccccc}
\hline & LD & NLD & & & \\
\cline { 2 - 3 } & $\%$ & $\%$ & & & \\
& & & & \\
\hline $\begin{array}{l}\text { I get along easily with others } \\
\text { my age (Child) }\end{array}$ & & & & & \\
$\quad$ False & 16.84 & 12.65 & & & \\
$\quad$ Sometimes & 39.42 & 31.27 & 2.68 & 1.00 & -- \\
$\quad$ True & 43.74 & 56.08 & & & \\
Others my age want me to & & & & & \\
be their friend (Child) & & & & & \\
$\quad$ False & 36.79 & 26.56 & & & \\
$\quad$ Sometimes & 30.43 & 35.30 & 2.40 & 1.00 & -- \\
$\quad$ True & 32.78 & 38.14 & & & \\
How many close friends does \\
your child have? (Parent)
\end{tabular}

Note: Bonferroni adjustment applied to $p$ values. Sample sizes for these analyses range from 119 to 196 for the LD group and 1789 to 2694 for the NLD group.

\section{Academic/School Experiences}

Student perceptions. Significant differences between groups were not found when students were asked how they felt about school and if their teachers treated them fairly. As well, the majority of students in both groups responded similarly that they rarely or never feel like an outsider (or left out of things) at school.

Parent perceptions. Significant differences between the responses of parents of students in the LD and NLD groups were found in terms of aspira- 
Table 3

Student Perceptions of the School Experiences of the

LD and NLD Samples

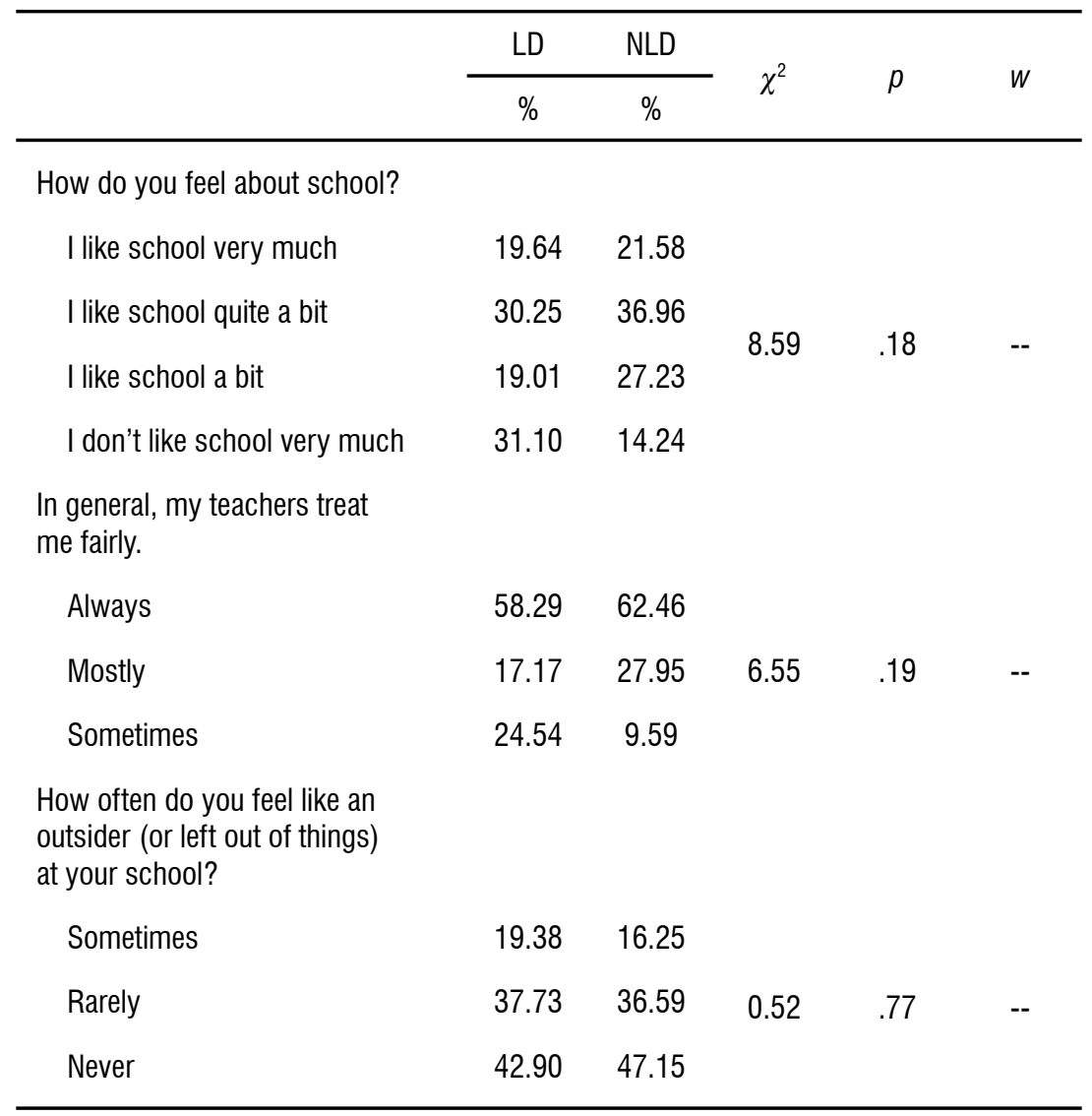

Note: Bonferroni adjustment applied to $p$ values. Sample sizes for these analyses range from 118 to 119 for the LD group and 2067 to 2089 for the NLD group.

tions for educational level completion $(p<.001)$. Specifically, the majority of parents of students in the NLD group hoped that their child would attend university while the majority of parents of students in the LD group hoped that their child would attend community college or university. Parents' report of how often they were involved in their child's homework also differed significantly across groups $(p<.01)$. Parents of students in the LD group checked or helped their child with their homework more often than parents of students in the NLD group. 
Table 4

Parent Perceptions of the School Experiences of the LD and NLD Samples

\begin{tabular}{cccccc}
$\mathrm{LD}$ & $\mathrm{NLD}$ & & & \\
\hline$\%$ & $\%$ & $\chi^{2}$ & $p$ & $w$
\end{tabular}

How far do you hope your child

will go in school?

\begin{tabular}{|c|c|c|c|c|c|}
\hline Secondary/High School Completion & 15.48 & 5.23 & \multirow[b]{3}{*}{28.12} & \multirow[b]{3}{*}{.001} & \multirow[b]{3}{*}{.082} \\
\hline Trade, Technical or Vocational School & 13.92 & 6.81 & & & \\
\hline $\begin{array}{l}\text { Community College, CEGEP or } \\
\text { Nursing School }\end{array}$ & 24.83 & 11.91 & & & \\
\hline $\begin{array}{l}\text { University } \\
\text { w often do you check/help with } \\
\text { mework? }\end{array}$ & 45.77 & 76.05 & & & \\
\hline Less than once per week & 20.30 & 30.91 & & & \\
\hline A few times per week & 18.76 & 24.70 & 12.50 & .01 & .056 \\
\hline Daily & 60.94 & 44.39 & & & \\
\hline
\end{tabular}

Note: Bonferroni adjustment applied to $p$ values. Sample sizes for these analyses range from 265 to 276 for the LD group and 3155 to 3829 for the NLD group.

Teacher perceptions. Responses from teachers of students in the LD and NLD groups differed significantly across all items. Teachers held lower educational aspirations for students in the LD group $(p<.001)$, felt that their parents were less involved in their education $(p<.001)$, and reported that these students put a lot of effort into work less often $(p<.001)$ than students in the NLD group.

\section{Discussion}

The results from the NLSCY regarding the experiences of students receiving special education services for LD provide valuable information from a national perspective. While several findings reported in the U.S. literature 
Table 5

Teacher Perceptions of the School Experiences of the

LD and NLD Samples

\begin{tabular}{ccccccc}
\hline & LD & NLD & & & \\
\cline { 2 - 3 } & $\%$ & $\%$ & & $p$ & $w$ \\
\hline
\end{tabular}

How far do you think this student has the potential to go in school?

Some Secondary

Secondary Completion

Learn a Trade (Apprenticeship)

College/University

How involved are the parents of this child in their education?

Very Involved

Sometimes Involved

Not Involved

How often does this student put a lot of effort into work?

Rarely

Sometimes

Often
$26.87 \quad 2.69$

$14.67 \quad 7.89$

$33.84 \quad 2.73$

$24.62 \quad 86.70$

$40.60 \quad 62.75$

$\begin{array}{lllll}43.86 & 34.34 & 17.40 & .001 & .067\end{array}$

$15.55 \quad 2.91$

$29.55 \quad 7.00$

$\begin{array}{lllll}41.12 & 23.93 & 37.53 & .001 & .094\end{array}$

$29.33 \quad 69.06$

Note: Sample sizes for these analyses range from 220 to 276 for the LD group and 3605 to 4004 for the NLD group.

are similar to those in the present study, results also contradict many of the assumptions held about students with LD.

\section{Student and Family Characteristics}

As has been reported in previous studies (Oswald et al., 2003; SEELS, 2002), there is a significantly greater proportion of boys in the LD sample 
compared to the NLD sample. However, the difference is not as great as that reported in U.S. studies, with 1.66 times as many boys as girls in the present LD sample compared to estimates of 2.05 from SEELS (2002).

In terms of SES, the LD group contains more families with less than high school education. Again, this finding has been substantiated in previous U.S. research (Blair \& Scott, 2002; Skiba et al., 2005). However, what is interesting to note is that similar proportions of families in the LD and the NLD group have completed higher levels of education. As well, income differences were only significant at the highest level. These findings, along with the parent reports of neighbourhood safety, suggest that most students in both groups have parents with at least post-secondary education, have mid-range incomes, and live in safe neighbourhoods. Thus, the suggestion that students may be identified and placed in special education for LD in part because of bias associated with a low-SES background does not appear to be borne out by the present results.

\section{Social Experiences}

Although extensive research exists documenting the negative social experiences of students with LD, the present findings do not fully substantiate these. Students in the LD and NLD groups share similar experiences in terms of getting along with others and perceiving others as desiring their friendship. Similarly, parents reported their children as having equal numbers of friends. In stark contrast to these findings, however, are the teacher reports of the social skills demonstrated by students in class. Students in the LD group were rated as having lower social skills than the NLD group. This finding may not be particularly surprising, however, as teachers are largely responsible for the referral of students to special education. While social skills deficits are not an essential part of most school-based definitions of LD, students with classroom behaviour problems and learning difficulties are more likely to be referred for special education than those who are solely struggling academically (Oswald et al., 2003; Shaywitz, Shaywitz, Fletcher, \& Escobar, 1990). Thus while students and parents report similar social experiences between the LD and NLD groups, teachers report significantly poorer skills for those with LD.

\section{Academic/School Experiences}

As with social experiences, significant differences did not emerge in the perceptions of students regarding school enjoyment, teacher fairness, and feel- 
ing like an outsider. Students in the LD group reported negative perceptions only at the most extreme response levels. It may be assumed that students would develop negative perceptions of school due to the academic failure that they have experienced and possibly continue to experience. However, as these students have not only been identified but are in fact receiving services for LD, the needs of the majority may have been met and they may be experiencing greater success in the classroom. The approximately $25 \%$ of students in the LD group who don't like school and who feel that their teacher does not mostly or always treat them fairly may continue to struggle because of the severity of the disability, or additional school or familial risk factors.

Parents of students with LD reported having significantly lower aspirations for their children than parents of students in the NLD group. However, the majority of parents in both groups hoped that their child would complete post-secondary education. As well, parents of students with LD reported supporting their child's learning through daily homework checks significantly more frequently than parents of the NLD group.

Parent aspirations may certainly have been influenced by those of their child's classroom teacher. Teachers reported having significantly lower aspirations for students in the LD group compared to the NLD group. Unfortunately, response options given to parents and teachers were quite different and direct comparisons cannot be made. Teachers felt that only $25 \%$ of students in the LD group compared to $87 \%$ of students in the NLD group had the potential to complete post-secondary education. While separate college and university options were given to teachers (as they were for parents), these two options had to be collapsed together due to the small numbers in the LD group and resulting coefficients of variation. This finding is somewhat surprising as the majority of post-secondary institutions offer programs specifically targeted at providing students with LD the supports they need to be successful (e.g., Carleton University, 2006; Simon Fraser University, 2003; University of Alberta, 2005; University of Prince Edward Island, 2004). As teacher beliefs regarding student potential impact the extent to which they are willing to adapt their instruction and assessment practices to better meet the needs of students with LD, low-level aspirations may certainly be detrimental for students with LD in terms of post-secondary enrolment.

Teachers also felt that parents of students with LD were much less involved in their child's education. A specific definition of "involvement" was not provided in the item. However it may be assumed that teachers would assess parent involvement through participation in school activities and levels of communication rather than at-home support. As teacher reports of low 
parent involvement have been found to negatively impact their perceptions of academic competence (Hughes, et al., 2005) and awarded reading grades (Feinberg, 2001), this finding is of concern. It is important that future research explore the assumptions and attributions that teachers make regarding the perceived lack of involvement of parents of students with LD, particularly in light of the higher rates of homework help/checking reported by parents of the LD group.

Finally, teachers felt that significantly more students in the LD group put effort into their work less often that those in the NLD group. Certainly students with LD may be less motivated and have lower academic self-concept due to past academic failure (Nowicki, 2003; Vaughn et al., 2001; Zeleke, 2004). However, research also shows that teacher ratings of effort are largely influenced by student achievement (Meltzer, Katzir-Cohen, Miller, \& Roditi, 2001). This raises the possibility that teachers may develop more negative perceptions of students with LD and place the onus solely on the student to improve academically. As students with LD are provided with learning strategies targeted to their individual needs and take ownership of these with the support and understanding of their teachers, their attempts will likely be more successful and result in a greater partnership in the classroom as well as increased motivation.

\section{Future Research}

Several lines of research emerge from the present findings. While most students with LD feel equally as positive regarding school as the students in the NLD group, a small group report not liking school and feeling less fairly treated by their teacher. This is an indicator of the disengagement of these students with their school, which is one of the early steps toward dropping out (Lan \& Lanthier, 2003). More research is necessary to determine what additional risk factors may be influencing the perceptions of this small group of students with LD in order for educators and parents to be able to work proactively to keep greater numbers of students with LD in school.

Related to student disengagement is the finding that teachers hold significantly lower aspirations for students with LD than those without. There are not sufficiently detailed questions in the NLSCY to allow for an examination of what these expectations are based on and what relationship they have to teacher practice. Smaller scale qualitative studies may be more suitable for tracing the development of teacher beliefs regarding the potential of students with LD. 


\section{Limitations}

A number of limitations are inherent in the use of secondary data such as those provided by the NLSCY. The present analyses were limited by the items included in the survey. There were many items that appeared to capture important elements of the school experiences of students with LD but low coefficients of variance prohibited their release. Also, teachers were responsible for identifying students in the LD group, and given that criteria is provincially mandated, their reports were certainly based on a range of definitions. Thus, student learning difficulties may vary in nature and severity across the country. Finally, the NLSCY, as with all surveys, is dependent on families choosing to participate. Thus, while representative geographically, the sample may not capture the experiences and characteristics of all students, for example those from very low-SES backgrounds or whose families have limited English proficiency or low literacy levels.

\section{Conclusion}

The demographic characteristics of students receiving special education services for LD are largely similar to students without disabilities. The overrepresentation of students from low-SES backgrounds in special education which has been reported in previous U.S. studies does not appear to be the case in Canada given the present findings. As well, students with LD report largely positive perceptions of peer relationships and school experiences as do students without LD. However, teachers perceive students as having lower social skills and exerting less effort in their school work and hold lower educational aspirations for students with LD compared to their peers without LD.

Clearly, efforts should continue to be made at the school and classroom levels to engage students with LD and equip them with appropriate learning strategies. Peer relationships are also particularly important for these students and findings indicate that this is an area of relative success for students in the present sample. This is a very promising finding. Other questions, however, are raised. Are teachers fully accepting of students with LD in their classroom? Do they have the resources, training, and support from parents and administration to best include them? Are students receiving special education services made to feel that their academic successes are worth as much as their peers? Is information regarding post-secondary programs and accommodations that specifically target students with LD being disseminated to parents and teachers? 
A final point which must be raised is the issue of class placement. Every province in Canada mandates educating all students in neighbourhood schools as a first placement option. However, individual provinces, school boards, and schools have chosen various settings in which to meet the needs of students with LD. These range from segregated schools to fully inclusive settings and within these, display heterogeneity in class composition, size, and teaching practices equal to that of "regular" settings. The NLSCY did include an item asking teachers to indicate where students received special education services in earlier versions and analyses using this variable have been completed recently (Whitley, 2007). The present analyses include students receiving special education services delivered in a variety of ways and while important in highlighting the experience of students with learning disabilities, points to the need for a longitudinal survey specifically created for students in special education such as that existing in the U.S. One of the most valuable contributions of surveys such as the NLSCY is to promote further research and to guide local examinations of national findings. The present findings can foster discussion and reflection among parents, educators, and administrators regarding the experiences of students receiving special education services for LD in their own schools.

\section{References}

Alberta Learning. (2004). Shaping the future for students with special needs: A review of special education in Alberta, final report. Edmonton, $A B$ : Author. Retrieved July 12, 2006, from http://www.education.gov.ab.ca/ k_12/special/SpecialEdReview/SpEdReport.pdf

Berry, C., Shaywitz, S., \& Shaywitz, B. (1985). Girls with attention deficit disorder: A silent minority? A report on behavioural and cognitive characteristics. Pediatrics, 76, 801-809.

Birch, S. H., \& Ladd, G. W. (1997). The teacher-child relationship and children's early school adjustment. Journal of School Psychology, 35, 6179.

Blair, C. \& Scott, K. G. (2002). Proportion of LD placements associated with low socioeconomic status: Evidence for a gradient? The Journal of Special Education, 36, 14-22.

Boardman, A. G. (2005). Interactions between teachers and students with learning disabilities in general education classrooms. Dissertation Ab- 
stracts International Section A: Humanities and Social Sciences, 65, 8-A, 2894.

British Columbia Ministry of Education (2000). A review of special education in British Columbia. Victoria: BC: Author.

British Columbia Ministry of Education (2006). Students with special needshow are we doing? Victoria, BC: Author.

Brody, G. H., Ge, X., Conger, R. D., Gibbons, F., Murry, V., Gerrard, M., \& Simons, R. (2001). The influence of neighborhood disadvantage, collective socialization, and parenting on African American children's affiliation with deviant peers. Child Development, 72, 1231-1246.

Buhs, E. S. (2005). Peer rejection, negative peer treatment, and school adjustment: Self-concept and classroom engagement as mediating processes. Journal of School Psychology, 43, 407-424.

Buhs, E. \& Ladd, G. W. (2001). Peer rejection in kindergarten: Relational processes mediating academic and emotional outcomes. Developmental Psychology, 37, 550-560.

Cadieux, A. (1996). Relationship between self-concept and classroom behavior among learning and nonlearning disabled students in regular classes. Perceptual and Motor Skills, 82, 1043-1050.

Carleton University. (2006). Paul Menton centre for students with disabilities. Retrieved July 15, 2006 from http://www.carleton.ca/pmc/learningdisabilities/index.html

Catsambis, S. (1998). Expanding the knowledge of parental involvement in secondary education: Effects on high school academic success. Baltimore: Center for Research on the Education of Students Placed At Risk.

Davis-Kean, P. E. (2005). The influence of parent education and family income on child achievement: The indirect role of parental expectations and the home environment. Journal of Family Psychology, 19, 294-304.

Duncan, G. J., \& Brooks-Gunn, J. (1997). Consequences of growing up poor. New York: Russell Sage Foundation.

Englund, M., Luckner, A., Whaley, G., \& Egeland, B. (2004). Children's achievement in early elementary school: Longitudinal effects of parental involvement, expectations, and quality of assistance. Journal of Educational Psychology, 96, 723-730.

Evans, G. W. (2004). The environment of childhood poverty. American Psychologist, 59, 77-92. 
Feinberg, D. L. (2001). Teachers' perceptions of parent involvement and student achievement and adjustment in high risk and low risk kindergarten students. Dissertation Abstracts International, 62 (01) (UMI No. 3002344).

Finn, J. D. (1993). School engagement and students at risk. Washington, DC: National Center for Education Statistics.

Freeman, E. B., \& Hatch, A. J. (1989). What schools expect young children to know and do: An analysis of kindergarten report cards. Elementary School Journal, 89, 595-605.

Fuchs, L. S., Fuchs, D., \& Phillips, N. (1994). The relation between teachers' beliefs about the importance of good student work habits, teacher planning, and student achievement. Elementary School Journal, 94, 331-345.

Hughes, J. N. Gleason, K. A., \& Zhang, D. (2005). Relationship influences on teachers' perceptions of academic competence in academically at-risk minority and majority first grade students. Journal of School Psychology, 43, 303-320.

Human Resources and Skills Development Canada. (October, 1996). National Longitudinal Survey of Children and Youth: Overview report. Ottawa, ON: Author.

Jordan, A., \& Stanovich, P. (2001). Patterns of teacher-student interaction in inclusive elementary classrooms and correlates with student self-concept. International Journal of Disability, Development, and Education, 48, 33-52.

Jussim, L., \& Harber, K. D. (2005). Teacher expectations and self-fulfilling prophesies: Knowns and unknowns, resolve and unresolved controversies. Personality and Social Psychology Review, 9, 131-155.

Karatzias, A., Power, K. G., Fleming, J., Lennan, F., \& Swanson, V. (2002) The role of demographics, personality variables and school stress in predicting school satisfaction / dissatisfaction: Review of the literature and research findings. Educational Psychology. An International Journal of Experimental Educational Psychology. 22, 33-50.

Kavale, K. A., \& Forness, S. R. (1996). Social skills deficits and learning disabilities: A meta-analysis. Journal of Learning Disabilities, 29, 226-237.

Lan, W., \& Lanthier, R. (2003). Changes in students' academic performance and perceptions of school and self before dropping out of schools. Journal of Education for Students Placed at Risk, 8, 309-332. 
Learning Disabilities Association of Canada. (2002). Official definition of learning disabilities. Retrieved May 12, 2005, from http://www.ldac-taac.ca/Defined/pdf/jan02eng.pdf

Lee, V. E. \& Burkam, D. T. (2002). Inequality at the starting gate: Social background differences in achievement as children begin school. Washington, DC: Economic Policy Institute.

Manitoba Education, Training and Youth (2001). Follow-up to the Manitoba special education review: Proposals for a policy, accountability and funding framework (detailed version). Winnipeg, MB: Author. Available at http://www.edu.gov.mb.ca/ks4/specedu/aep/pdf/long.pdf

Meltzer, L., Katzir-Cohen, T., Miller, L., \& Roditi, B. (2001). The impact of effort and strategy use on academic performance: Student and teacher perceptions. Learning Disability Quarterly, 24, 85-98.

Meltzer, L., Reddy, R., Pollica, L. S., Roditi, B., Sayer, J., \& Theokas, C. (2004). Positive and negative self-perceptions: Is there a cyclical relationship between teachers' and students' perceptions of effort, strategy use, and academic performance? Learning Disabilities Research and Practice, 19, 33-44.

National Longitudinal Transition Study-2 [NLTS-2] (2005). Facts from NLTS2: High school completion by youth with disabilities. Menlo Park, CA: SRI International. Retrieved November 11, 2005, from www.nlts2.org/pdfs/selfdeterm_factsheet_112305.pdf

Nass, R. D. (1993). Sex differences in learning abilities and disabilities. Annals of Dyslexia, 43, 61-77.

Nova Scotia Department of Education (2003). Effective special education programming and services: Response to the report of the special education implementation review committee. Halifax, NS: Author. Available at http://www.ednet.ns.ca/index.php?sid=369947329\&t=sub_pages\&cat=83

Nowicki, E. A. (2003). A meta-analysis of the social competence of children with learning disabilities compared to classmates of low and average to high achievement. Learning Disability Quarterly, 26, 171-188.

Ontario Ministry of Education and Training (2005). Early school leavers: Understanding the lived reality of student disengagement from secondary school. Toronto, ON: Author.

Ontario Ministry of Education (2006). Special education transformation. Toronto, ON: Author. 
Oswald, D. P., Best, A. M., Coutinho, M. J., \& Nagle, H. A. L. (2003). Trends in the special education identification rates of boys and girls: A call for research and change. Exceptionality, 11, 223-237.

Patrikakou, E. N. (1996). Investigating the academic achievement of adolescents with learning disabilities: A structural modeling approach. Journal of Educational Psychology, 88, 435-450.

Rao, J. N. K., \& Scott, A. J. (1987). On simple adjustments to chi-square tests with sample survey data. The Annals of Statistics, 15, 385-397.

Sampson, R., Raudenbush, S., \& Earls, F. (1997). Neighborhoods and violent crime: A multilevel study of collective efficacy. Science, 277, 918-924.

Saskatchewan Learning (2000). Directions for diversity: Enhancing supports to children and youth with diverse needs. Regina, SK: Author. Available at http://www.publications.gov.sk.ca/details.cfm?p=10114

Shaywitz, S., Shaywitz, B., Fletcher, J., \& Escobar, M. (1990). Prevalence of reading disability in boys and girls: Results of the Connecticut longitudinal study. Journal of the American Medical Association, 264, 998-1002.

Shaywitz, S., Towle, V., Keese, D., \& Shaywitz, B. (1990). Prevalence of dyslexia in boys and girls in an epidemiologic sample. Journal of the American Medical Association, 264, 143-157.

Simcha-Fagan, O., \& Schwartz, J. E. (1986). Neighborhood and delinquency: An assessment of contextual effects. Criminology, 24, 667-703.

Simon Fraser University. (2003). Accessibility for students with disabilities policy. Retrieved July 15, 2006, from

http://www.sfu.ca/policies/general/gp26.htm

Sinclair, M. F. (1994). Are we pushing students in special education to drop out of school? Washington, DC: Special Education Programs.

Skiba, R. J., Poloni-Staudinger, L., Simmons, A. B., Feggins-Azziz, R., \& Chung, C-G. (2005). Unproven links: Can poverty explain ethnic disproportionality in special education? The Journal of Special Education, 39, 130-144.

Special Education Elementary Longitudinal Study. (2002). SEELS data tables. Available at: http://www.seels.net

Smith, D. S., \& Nagle, R. J. (1995). Self-perceptions and social comparisons among children with LD. Journal of Learning Disabilities, 28, 364-371. 
Statistics Canada (1997). National Longitudinal Survey of Children \& Youth: Overview of survey instruments for 1996-97 data collection, Cycle 2. Catalogue no. 89FOO78XIE.

Statistics Canada. (2001a). Microdata user guide. National Longitudinal Survey of Children and Youth. Cycle 4 September 2000 to May 2001. Ottawa, ON: Author.

Statistics Canada (2001b). Microdata user guide. National Longitudinal Survey of Children and Youth: Secondary File. Cycle 4 September 2000 to May 2001. Ottawa, ON: Author.

Statistics Canada (2003). Microdata user guide. National Longitudinal Survey of Children and Youth. Cycle 5. September 2002 to June 2003. Ottawa, ON: Author.

Sy, S. R., \& Schulenberg, J. E. (2005). Parent beliefs and children's achievement trajectories during the transition to school in Asian American and European American families. International Journal of Behavioral Development, 29, 505-515.

University of Alberta. (2005). Programs for students with learning disabilities. Retrieved July 15, 2006, from http://www.uofaweb.ualberta.ca/SSDS/psld.cfm

University of Prince Edward Island (2004). Services for students with disabilities. Retrieved July 15, 2006, from http://www.upei.ca/disabilities

Vaughn, S., Elbaum, B., \& Boardman, A. G. (2001). The social functioning of students with learning disabilities: Implications for inclusion. Exceptionality, 9, 47-66.

Volker, M. A. (2006). Reporting effect size estimates in school psychology research. Psychology in the Schools, 43, 653-672.

Wagner, M., Kutash, K., Duchnowski, A. J., \& Epstein, M. H, (2005). The special education elementary longitudinal study and the national longitudinal transition study: Study designs and implications for children and youth with emotional disturbance. Journal of Emotional and Behavioral Disorders, 13, 25-41.

Wagner, M., Kutash, K., Duchnowski, A. J., Epstein, M. H., \& Sumi, W. C. (2005). The children and youth we serve: A national picture of the characteristics of students with emotional disturbances receiving special education. Journal of Emotional and Behavioral Disorders, 13, 79-96. 
Wang, M. C., Haertel, G. D., \& Walberg, H. J. (1990). What influences learning? A content analysis of review literature. Journal of Educational Research, 84, 30-43.

Wehmeyer, M. L. \& Schwartz, M. (2001). Disproportionate representation of males in special education services: Biology, behaviour or bias? Education and Treatment of Children, 24, 28-45.

Wentzel, K. R. (1993). Does being good make the grade? Social behavior and academic competence in middle school. Journal of Educational Psychology, 85, 357-364.

Wentzel, K. R., Barry, C. M., \& Caldwell, K. A. (2004). Friendships in middle school: Influences on motivation and school adjustment. Journal of Educational Psychology, 96, 195-203.

Wentzel, K. R. \& Caldwell, K. (1997). Friendships, peer acceptance, and group membership: Relations to academic achievement in middle school. Child Development, 68, 1198-1209.

Wentzel, K. R. \& Watkins, D. E. (2002). Peer relationships and collaborative learning as contexts for academic enablers. School Psychology Review, 31, 366-377.

Westat (2000). WesVar 4.0, User's Guide. Rockville: Westat, Inc.

Whitley, J. (2007). A model of general self-concept for students with learning disabilities: Does class placement play a role? Manuscript submitted for publication.

Zeleke, S. (2004). Self-concepts of students with learning disabilities and their normally achieving peers: A review. European Journal of Special Needs Education, 19, 145-170.

\section{Authors' Note}

Correspondence regarding this manuscript should be addressed to: Jessica Whitley, Assistant Professor, Faculty of Education, Lakehead University, 955 Oliver Rd, Thunder Bay, ON, P7B 5E1. Email: jwhitley@lakeheadu.ca. 
Whitley, Lupart \& Beran

110 Exceptionality Education Canada, 2007, Vol. 17, No. 3 